\title{
EL MONSTRUO HUMANO. EL YO HOMOSEXUAL EN EL AMOR DEL REVÉS (2016), DE LUISGÉ MARTÍN
}

\author{
Carlos Alayón Galindo \\ calayongalindo@gmail.com
}

\section{Resumen}

El presente trabajo tiene por objeto el estudio de El amor del revés (2016), de Luisgé Martín. Esta autobiografía será abordada no solo como texto literario, sino también como un ejercicio testimonial que da cuenta de lo que significó ser un hombre homosexual durante la transición hacia la democracia y los años posteriores. El interés analítico recaerá, sobre todo, en ver cómo interactúan nociones como la homosexualidad o la de diferencia. Se centrará la atención en todos aquellos elementos identitarios que, en la página, configuran la voz de ese $y o$ autobiógrafo que se sabe homosexual y que se escribe desde dicha posición. Para ello aplicaremos un enfoque sociológico que bebe de las ideas de autores como Brubaker y Cooper, Guasch, Eribon o Mira.

PALABRAS Clave: autobiografía, escrituras del yo, Luisgé Martín, homosexualidad, siglo xxi.

THE HUMAN MONSTER. HOMOSEXUAL SELF

IN LUISGÉ MARTIIN'S EL AMOR DEL REVÉS (2016)

\section{Abstract}

The aim of this research is to study Luisgé Martin's El amor del revés. This autobiography will be approached not only as a literary text, but also as a testimony of what it meant to be a homosexual man in the early Spanish democracy and in the following years. Therefore, the analysis will be centered on the interaction between concepts like homosexuality and difference. It will be focused on those identity elements that shape the autobiographer's self, and the voice that recognizes itself as homosexual and writes itself from that position. In order to achieve that objective, a sociological approximation based on the ideas of scholars such as Brubaker, Cooper, Guasch, Eribon and Mira will be applied.

KeYwORDs: autobiography, Luisgé Martín, homosexuality, self-writings, xxi century.

DOI: https://doi.org/10.25145/j.clepsydra.2021.21.04

Revista Clepsydra, 21; marzo 2021, pp. 73-93; ISSN: e-2530-8424 
Para que un monstruo se cree, algo tiene que fallar al principio de la historia.

Charlie Fox

\section{INTRODUCCIÓN}

En la literatura española, la autobiografía tuvo un gran auge en las últimas décadas del siglo xx. Como constatan David y Burdiel, «la eclosión de los géneros biográficos y autobiográficos» se da "en los años setenta y ochenta, coincidiendo con la transición de la dictadura a la democracia» (18). Los motivos de este fenómeno atienden a cuestiones de carácter histórico, político y cultural. Romera Castillo señala como causas fundamentales «la mayor libertad de expresión» tras la muerte del dictador, la necesidad y urgencia de los escritores de recomponer el pasado fragmentado, «la reivindicación del individualismo» y el «decaimiento de la ficción", entre otras (22). Hemos de tener en cuenta que este reciente interés por lo autobiográfico no implica que en épocas pasadas no se produjeran textos de esta índole. Estudios como el de Durán López acerca de la autobiografía española en los siglos XVIII y XIX ya desmienten ese «tópico de la escasa afición» de la tradición hispana por la escritura autobiográfica frente a otras como la anglosajona (Caballé 131). De esta manera podemos contar hoy con una lista casi infinita de personalidades que han transitado el espacio del yo, como podrían ser Rosa Chacel, Rafael Alberti, Carlos Castilla del Pino, Jorge Semprún, José Manuel Caballero Bonald, Carlos Barral, Francisco Umbral o Rosa Montero. Es interesante resaltar, llegados a este punto, la popularidad con la que cuenta esta forma de autoescritura dentro de la literatura gay ${ }^{1}$ en nuestro país. Una gran mayoría de escritores homosexuales se han adentrado, antes o después, en el género autobiográfico ya que reúne las condiciones necesarias para explorar las diferentes formas en las que la sexualidad moderna es representada y cómo «sexual identity and sexual practice are defined, negotiated, and experienced in contemporary society" (Ellis 1). Es el caso, por ejemplo, de Juan Goytisolo, Terenci Moix, Vicente Molina Foix, Luis Antonio de Villena o Luisgé Martín, autor que aquí nos ocupa.

Su escritura se caracteriza, casi desde sus inicios, por la necesidad de jugar con esa fina línea que separa la realidad de la ficción, de colarse en la brecha entre lo verídico y el simulacro. Prueba de esto que comentamos son obras como Las manos cortadas (2009) o La misma ciudad (2013). En líneas generales suele seguir dos procedimientos bien delimitados: o ficcionaliza su propia vida, como ocurre en

${ }^{1}$ El concepto de literatura gay debe ser entendido como una práctica literaria que conlleva una serie de procesos identitarios conscientes. Ello implica que la simple aproximación estética o la tematización de la homosexualidad no es criterio suficiente para figurar en este gran corpus. En palabras de Gregory Woods, «en esencia, de lo que aquí estamos hablando es de la creación deliberada de una tradición homosexual» (12). 
Los amores confiados (2005), o bien se presenta a sí mismo como narrador testigo y partícipe de los hechos imaginados que expone, tal y como vemos en La vida equivocada (2015), novela en la que se convierte en un personaje más y cuenta las desventuras de Max Leopardi, un intento fallido de escritor.

En su literatura, por tanto, siempre hay, en mayor o menor grado, cierta intromisión del yo. Sin embargo, en El amor del revés (2016) el planteamiento es radicalmente diferente. Ya no estamos ante un juego literario de autoficción, sino ante el relato de la propia vida. Esta obra es la historia de un descubrimiento y de sus consecuencias. En ella, nos encontramos con una cucaracha, Luisgé Martín, que, a los quince años, toma conciencia de su verdadera naturaleza: es un insecto exótico, es homosexual. A partir de ahí, llega el silencio y el secreto. Ese deseo torcido, anormal, que siente no tiene cabida alguna en aquella España que comienza a despertar del letargo franquista. Con el paso del tiempo, la cucaracha se va convirtiendo, poco a poco, en un ser humano. Se deshace de su exoesqueleto, de sus antenas y, sobre todo, de sus miedos y prejuicios. Nombres como Miguel Ángel, Jesús, Arturo -su gran amor-, Antonio o Axier son cruciales en esta transformación. Gracias al viaje que realiza el yo y al cambio que este lleva aparejado, podemos apreciar también la apertura de la sociedad española a fenómenos que, como la homosexualidad, permanecieron acallados durante la dictadura.

Dicho esto, estableceremos el interés de la obra del madrileño en la exposición de un testimonio autobiográfico que emana única y exclusivamente de su identidad como sujeto gay. Luisgé Martín decide escribirse de manera pretendida y consciente desde esta perspectiva y plasmar el traumático proceso de aceptación de su verdadero ser. Todo queda subordinado a su experiencia de la homosexualidad; de ahí que nuestro objeto de estudio se centre en esclarecer qué elementos identitarios y códigos utiliza para crear textualmente ese yo homosexual. Ahondaremos, por tanto, en su valor como testimonio, ya resaltado por críticos como Sanz Villanueva, quien afirmó: «la autobiografía de Luisgé Martín servirá algún día como documento sociológico imprescindible para la reconstrucción de la mentalidad de la España del último trecho del pasado siglo» (párr. 3). Nuestra aproximación se centrará en diversas cuestiones como, por ejemplo, la disección de los discursos que en los últimos ańos de la dictadura circulaban en torno a la homosexualidad, la recepción de estos por parte de la subjetividad del autor y las consecuencias que tuvieron, es decir, en qué grado afectaron a la autopercepción de ese yo que se construye a través de lo monstruoso y a su interacción con el entorno. Este enfoque parte de la idea de autobiografía "como una forma esencial de compresión de los principios organizativos de la experiencia, de nuestros modos de interpretación de la realidad histórica en que vivimos» (Loureiro 2). 


\section{EL AMOR TORCIDO: IDENTIDAD, DISCURSOS Y FIGURACIONES EN TORNO A LA HOMOSEXUALIDAD}

El yo autobiográfico - monstruo híbrido, mitad verdad, mitad artificioasume según se van sucediendo las páginas una identidad determinada. Para poder estudiar esta construcción debemos establecer alguna que otra aclaración terminológica. El concepto de identidad ha sido usado en tantos contextos y se han referido tantas realidades en su nombre que se ha convertido en una entidad pantanosa, emborronada. Hablamos, así, de identidades nacionales, identidades sexuales, de la identidad como expresión de la subjetividad de un individuo o también de un colectivo. Estos son solo algunos ejemplos de lo amplio que es su campo de aplicación. Si queremos usar esta noción desde un punto de vista analítico, primero debemos acotar su significado y dejar de lado todos esos contenidos impresionistas que se le han presupuesto. Para discernir los posibles inconvenientes semánticos con respecto a esta idea, aplicaremos la propuesta de Brubaker y Cooper en su conocido artículo «Beyond identity» (2000).

Los autores norteamericanos proponen, desde la Sociología, una configuración tripartita del término. De esta manera, debemos atender a tres preceptos fundamentales que constituyen la identidad de un sujeto: el primero de ellos, la identificación y la categorización por parte de otros-identification and categorization, en el original-, es un proceso complejo que implica diversas variantes y que surge de la superposición de discursos a lo largo del tiempo en torno a una misma categoría social, "external identification is itself a varied process»; el segundo es el self-knowning, es decir, el conocimiento de uno mismo, la concepción que se tiene de sí; y, por último, el tercero se corresponde con el sentido de pertenencia a un grupo característico (sense of belonging) (Brubaker y Cooper 19).

En este apartado, el concepto de identidad que hemos establecido se estudiará en relación con el de homosexualidad masculina. Este último debe entenderse como una categoría social construida a través de los siglos que se define por ser el resultado de un proceso de sujeción del individuo a partir de una serie de prácticas sexoafectivas y culturales. La homosexualidad a la que aquí nos referimos es una entelequia abstracta, una forma que engloba expresiones identitarias concretas y subjetivas, como un ejemplo o "modelo», si usamos las palabras de Alberto Mira. Para este crítico español, por ejemplo, se deducen tres arquetipos tradicionales de homosexual, tres ejes creados a partir de las diversas conceptualizaciones de dicha categoría en las sociedades occidentales: «el malditista» o rebelde que acepta su condición de marginado; «el homófilo» que lucha por la integración en la normalidad del paradigma homosexual, y, por último, el modelo «camp», que cuestiona, desde la ironía, los «imperativos morales» de las dos clasificaciones anteriores (Mira 24-26).

Aparte de abstracta, la naturaleza de dicho término es, también, mítica. La idea de mito, defendida por Óscar Guasch (2007), nos remite al fenómeno de la narración como tecnología de lo identitario. Hemos de tener en cuenta que su propuesta no se circunscribe exclusivamente al ámbito homosexual, la heterosexualidad y cualquier otra categoría sexual solo existen en el terreno discursivo: "Con la homosexualidad sucede lo mismo [que con la heterosexualidad]. Como en Las Mil 
y una noches, la homosexualidad es un cuento dentro de otro cuento, un relato dentro de otro, un mito que explica otro mito» (Guasch, La crisis 20). A pesar de lo que se podría llegar a pensar, dicho mito no es universal, o sea, no es transhistórico ni tampoco común a todas las sociedades. Para evitar disposiciones etnocéntricas innecesarias se debe comprender que «al igual que la heterosexualidad, la homosexualidad es un producto de nuestra época que no puede buscarse más allá de nuestra cultura» (Guasch, La crisis 21).

El diálogo entre las dos ideas que hemos planteado en este apartado nos permite una honda aproximación al texto de Luisgé Martín. Para el autor madrileño, el concepto de identidad está estrechamente ligado a la sexualidad; no hay un yo si no hay deseo: «un ejercicio que considero exquisitamente humano: la experiencia erótica proscrita y reprobada; la sexualidad torcida. Sólo en él se puede descubrir la hondura verdadera de lo que fingimos ser y de lo que en realidad somos» (Martín, El amor 192). Por ello, los presupuestos teóricos de Brubaker y Cooper, así como los de académicos como Guasch y Mira, interactúan a la perfección con el contenido presente en El amor del revés.

\subsection{JUECES, PSIQUIATRAS Y SACERDOTES: HOMOSEXUALIDAD Y TARDOFRANQUISMO}

Mientras que en el resto de países comenzaba ya en los setenta el resbaladizo camino hacia la autodeterminación y la conquista de derechos de la comunidad LGBTI, en Espańa la situación era sumamente diferente. El tardofranquismo se caracterizó por una mayor apertura, por una disociación entre la moral impuesta por el régimen y las actitudes, cada vez más abiertas y tolerantes, de la población civil urbana (Guasch, La sociedad 43). Un ejemplo claro nos lo aporta el retrato que hace Luisgé Martín de su familia en las postrimerías de la dictadura:

Mi familia nunca tuvo beatería. Mis padres eran católicos y creían que la forma de vida cristiana nos llevaría a todos a la eternidad, pero a la hora de interpretar los mandamientos de Dios siempre hubo cierta cordura. Mi madre se burlaba en cualquier circunstancia del papel sumiso de la mujer predicado en la época, y mi padre hacía esfuerzos más voluntariosos que reales por educarnos con severidad doctrinal (El amor 26-27).

Sin embargo, en el ámbito de las libertades sexuales se vivió un momento de auténtica "miseria» (Aliaga y Cortés 19). La arquitectura represiva del régimen dictatorial tuvo en la sociedad española un gran arraigo. Su rápido desmantelamiento a nivel jurídico y político durante la etapa de la Transición no se dio con tanta facilidad en la esfera social. La forma mentis de la época tenía costumbres, maneras y pautas heredadas de los primeros estadios del régimen como, por ejemplo, la escisión entre sexos, la reducción de la mujer a lo doméstico, «la pudibundez extrema y un sentido del recato enfermizo» (Aliaga y Cortés 35). La tajante separación entre el ámbito privado y el público, también, fue una de las actitudes más difíciles de combatir de todo este sistema. Ello conllevó que «la ocultación de las infracciones come- 
tidas contra las normas de respetabilidad y decoro convencionales» se convirtiera casi en una obsesión para las gentes de a pie (Aliaga y Cortés 36). Los diferentes puntos que hemos mencionado nos remiten a una sociedad persecutoria, asfixiante, en la que la categorización del homosexual, como puede imaginarse, orbitaba en torno a valores siempre negativos. La corrupción, el vicio y la degeneración de la conducta social eran constantes semánticas que circunscribían la definición del sujeto gay. Expondremos, con suma brevedad, varios ejemplos pertenecientes al ámbito jurídico que corroboran lo que aquí comentamos.

El primero se corresponde con la Ley de Vagos y Maleantes, predecesora de la que sería en 1970 la Ley de Peligrosidad y Rehabilitación Social (LPRS). Aunque ya estaba vigente durante la Segunda República, nos interesa la reforma aprobada en plena dictadura, la de 1954. Su consigna era la de erradicar los actos que ofendieran «a la sana moral de nuestro país por el agravio que causan al tradicional acervo de buenas costumbres, fielmente mantenido en la sociedad española» (Ley de Vagos y Maleantes). Los artículos reformulados en esta revisión que más enjundia presentan para el asunto que aquí nos compete son el 2 y el 6 . En el artículo 2, se equipara la figura del homosexual con la de «rufianes y proxenetas» para luego, en el 6, ampliar la comparación «a los mendigos profesionales y a los que vivan de la mendicidad ajena, exploten menores de edad, enfermos mentales o lisiados» (Ley de Vagos y Maleantes). De ser detectadas por las fuerzas del orden, todas estas formas de delincuencia y vandalismo tenían graves castigos: algunos eran condenados en lo que se llamó "establecimiento de trabajo», otros en las "colonia[s] agrícola $[s] »$. Los homosexuales, por su parte, debían ser internados «en instituciones especiales y, en todo caso, con absoluta separación de los demás» (Ley de Vagos y Maleantes). El homosexual, a partir de este discurso jurídico, queda dibujado en el imaginario colectivo como un sujeto criminal que requiere una corrección de sus prácticas desviadas.

El segundo ejemplo al que haremos referencia se da ya en los últimos momentos del franquismo. El 1 de febrero de 1971 se aprobó una Orden del Ministerio de Educación y Ciencia en la que «se recoge que el homosexualismo [...], en tanto que defecto físico o enfermedad, impide ejercer de maestro en la enseñanza primaria» (Aliaga y Cortés 30). La mención exclusiva a ese periodo de aprendizaje activa uno de los estereotipos homófobos más difundidos, es decir, se vuelve sobre la idea del homosexual como pederasta, como corruptor de menores. El tercer, y último, caso propuesto es la confirmación definitiva de que los estragos de la dictadura se sintieron todavía en plena democracia. Nos referimos aquí al proceso al que fue sometido en la década de los ochenta José Ramón González Lacalle, capitán de Aviación. $\mathrm{Su}$ «conducta homosexual» lo condujo a «seis meses y un día de prisión militar y a la separación del servicio por un delito consumado contra el honor militar» (Cuadra párr. 2). De nuevo, la homosexualidad como delito y el homosexual, como reo.

Estos casos de naturaleza jurídica se ven apoyados por discursos de índole médica y religiosa. Ambos suponen el respaldo científico y moral, respectivamente, a esas concepciones establecidas en la ley. En cuanto al ámbito médico, hemos de decir que la disciplina que más empeño puso en el estudio del homosexual fue la Psiquiatría. A partir de consideraciones esencialistas y, por supuesto, de criterios 
acientíficos, grandes nombres de la medicina española como Juan José López Ibor o Antonio Vallejo Nájera cargaron en contra de todo aquel que presentase semejante conducta. En general, las conclusiones de los psiquiatras fueron cambiando con el tiempo: «se pasa de un modelo homofóbico de desprecio a uno preocupado por la curación» (Mira 301). De una forma o de otra, el homosexual siempre era un sujeto no aceptado. Luisgé Martín hereda los últimos vestigios de esto que mencionamos. Encontramos, en los recuerdos de su infancia, que el escritor alude a una enciclopedia referente en la cultura española en la que podemos evidenciar que se da ya un tratamiento más laxo:

La enciclopedia La medicina y la salud publicada por Salvat en 1973, [...] había sido objeto de una revisión ética dirigida por Manuel Alcalá, profesor de Moral en las universidades de Comillas y de Granada, pero no tenía un tono inquisitorial, sino más bien indulgente (Martín, El amor 31).

Otra secuencia que ratifica ese intersticio entre dos moralidades, ese tiempo bisagra en el que vivió Martín, lo hallamos en la primera sesión con su psicólogo. En ella podemos ver claramente el estado de la cuestión en aquella época de transiciones. Por un lado, podemos comprobar que la American Psychological Association (APA), en 1973, decide eliminar la homosexualidad de su Manual diagnóstico de los trastornos mentales, es decir, ya no es concebida como una patología que requiera cura. Por otro, somos testigos de que todavía entonces había ciertos prejuicios latentes $^{2}$. El ejemplo más obvio es el mantenimiento de las terapias de reconversión en las que el paciente era sometido a una serie de rutinas -algunas físicamente inofensivas, otras no tanto- para reeducar su conducta y así poder reinsertarse adecuadamente en la sociedad:

El psicólogo al que había sido asignado, que se llamaba Miguel, me escuchó con atención, me hizo preguntas acerca de mi vida familiar y de mi entorno, y me explicó luego, con vehemencia, que la homosexualidad no era una patología y que sentirse atraído por los hombres no podía considerarse objetivamente una cuestión clínica. No obstante, dijo, si para mí suponía un conflicto social por la imposibilidad de adaptarme a las pautas de convivencia establecidas, podíamos iniciar el tratamiento (Martín, El amor 105).

En el terreno de la moral y de la ética, fue la Iglesia católica la que mayor impacto tuvo en el imaginario colectivo. Su defensa de la heterosexualidad como institución sexoafectiva natural, de la finalidad exclusivamente reproductiva del sexo, de la lectura biologicista de los cuerpos, de la separación de los sexos y, también, su

2 Terenci Moix es otro autor que corrobora, a través de sus memorias, el prejuicio de la Psicología: «Desde el momento en que intuyó el origen de mis males, se esfumó de su rostro el menor indicio de simpatía. [...] Me lo dijo abiertamente [...] yo era víctima de una aberración que era necesario extirpar sin tardanza. [...] Estaba hablando de no sé cuántos métodos para cambiarme. Habló de electroshocks» (532). 
desconfianza hacia todo lo relacionado con el deseo y el cuerpo hacen que la figura del homosexual se convierta en un problema difícil de encajar en dicho esquema. De esta manera, la práctica de la homosexualidad queda englobada "en el ámbito del pecado" (Guasch, La crisis 39). Sin duda, de todos los discursos que hemos barajado y de todas las figuraciones de la homosexualidad que hemos referido, es esta última, la de la homosexualidad como pecado, la que mayor impacto tiene en el testimonio de Luisgé Martín. Para el autor, educado en el colegio católico de San Viator de Madrid durante toda su infancia y adolescencia, la naturaleza punitiva y demoniaca de este «amor torcido» es una de las cuestiones que más le perturbaban a su primer yo: «los tratos degenerados y sucios que al parecer se daban entre personas del mismo sexo eran de naturaleza carnal, deshonestos, inducidos en el mejor de los casos por las potencias vegetativas que compartimos con las bestias o [...] por Mefistófeles» (Martín, El amor 17). Las constantes pesquisas del padre Jaime, «iTe tocas la colita?», y su ferviente amor por su compañero de clase, Miguel Ángel, hacen que nuestro autor vuelva a buscar respuestas en los libros (15). Al igual que con la enciclopedia Salvat, Martín consulta la Teología moral para seglares para conocer el origen de su desviación. Aquí un ejemplo:

Yo, que estaba aterrorizado por el infierno y por los pecados de mi espíritu, comencé a leer en secreto pasajes más carnales para tentar a mi suerte. No me interesaban los sacramentos, las virtudes teologales o la justicia social, de los que hablaba con prolijidad el libro, sino la sexualidad y sus castigos. El texto, que tenía un lenguaje deliciosamente reglamentario, casi forense, era estremecedor: atribuía todos los males a quienes como yo sufrían de esos extravíos eróticos (27).

Y continúa diciendo:

De los diez pecados posibles, a mí me afectaban sólo dos: la polución -que era como se denominaba en el libro a la masturbación solitaria, puesto que el onanismo exigía una unión sexual entre dos personas- y la sodomía. [...] El segundo, el de la sodomía, era el que amedrentaba, el que guiaba en aquellos tiempos todas mis pesadillas, pero la Teología moral para seglares le dedicaba sólo dos párrafos (28).

Aunque breves, estos pasajes ponen de manifiesto la recuperación y popularización del arquetipo del sodomita durante el periodo franquista. Este término, de origen judío y de larga evolución histórica, siempre ha estado relacionado con «las prácticas sexuales no ortodoxas», convirtiéndose así en uno «de los pecados más graves de lujuria» (Guasch, La crisis 40). El sodomita es una categoría amplia que en sus inicios aglutinaba todo acto sexual "contrario a la naturaleza»; de ahí que bajo este marbete se incluyeran conductas como la homosexualidad o el bestialismo (Guasch, La crisis 40). Luego, el vocablo se especializó para referirse en exclusiva al sexo entre hombres ${ }^{3}$. Estipulado ya el pecado y el pecador, llegó la culpa y la vergüenza. De este

\footnotetext{
${ }_{3}$ Normalmente, este concepto ha estado relacionado siempre al ámbito masculino. Ello se debe a que el placer femenino, y por ende las identidades lesbianas, ha sido negado y olvidado
} 
modo, sobre los homosexuales recae un poderoso estigma. Goffman define etimológicamente la noción de 'estigma' como una serie de «signos corporales con los cuales se intentaba exhibir algo malo y poco habitual en el estatus moral de quien los presentaba», marcando a sus portadores como una "persona corrupta, ritualmente deshonrada» (11). En este caso, la carga semántica del concepto subraya, sobre todo, la tara moral. El peso de este sistema de pensamiento se deja entrever, también, en El amor del revés. El autor cuenta el caso de Alfonso, un joven gay de familia conservadora, que, acusado por este tipo de creencias, se obligó a adoptar una pose de mujeriego e incluso a casarse. Luisgé Martín lo propone como paradigma del conflicto interno que los homosexuales vivían en su época: «Decía que estaba orgulloso de ser como era, pero sentía aún culpa y vergüenza. Le roía esa contradicción, esa incapacidad para desprenderse de las hechicerías en las que le habían educado» ( $E l$ amor 26). Alfonso, al final, acabó suicidándose.

Como hemos podido comprobar, el castigo legal, la medicalización y patologización de la sexualidad y el peso de la moral cristiana convirtieron la existencia homosexual en la época franquista en una suerte de imposible, lo convirtieron en un «amor difícil» para nuestro protagonista (Martín, El amor 90). España estuvo todo ese tiempo, e incluso durante la Transición y primeros ańos de democracia, en lo que se conoce como la etapa "pre-gay» (Guasch, La sociedad 47). Ello implica que la homosexualidad se explicaba a partir de preceptos heterosexuales, es decir, no se había dado «la toma de conciencia del homosexual de su propia condición» (Guasch, La sociedad 48). La definición impuesta por la norma suele ir ligada a profundos criterios sexistas y presunciones negativas en torno a dicha categoría. Además, lleva aparejado un proceso de invisibilización en el que la persona gay es erradicada de la vida pública y, por supuesto, del «espacio mediático» (Aliaga y Cortés 36). Los referentes homosexuales eran inexistentes:

No había otros homosexuales en la vida corriente, en las aulas de un colegio religioso o de un instituto público de bachillerato, en las calles de barrio, en los bares a los que iba con mis amigos a beber un refresco o una cerveza, en las playas del verano, en los cines de Gran Vía, en las casas de mi vecindario. [...] No había personajes literarios ni cinematográficos, no había reyes ni cantantes ni deportistas famosos que tuvieran la misma tara (Martín, El amor 44).

Hemos de tener en cuenta que todas estas figuraciones tuvieron un gran arraigo en la visión que el autor tuvo de sí mismo y de sus iguales. La visión esencialmente trágica, negativa e imposible de la figura del homosexual fue difícil de erradicar. Aunque «después de la muerte de Franco, España empezó a mudar poco a poco su piel de lagarto», para Luisgé Martín, esa idea de los gais como «criaturas tristes y abandonadas, paranoicos, chiflados, pederastas, patrañeros, embaucadores,

por la tradición judeocristiana. Al respecto, Llamas comenta: «Los gais son sólo cuerpo; las lesbianas, ni eso» (153). 
delincuentes, pornógrafos, majaderos» se convierte en un tormento, en una cruz con la que tiene que batallar día a día (El amor 30-49).

\subsection{NORMA, HOMBRE Y MONSTRUO: EL YO Y LA HOMOSEXUALIDAD}

Durante la época dictatorial, el «heterocentrismo incuestionado» que fundamenta nuestra cultura patriarcal se vio reafirmado (Rich 16). Es el hombre heterosexual el que define al resto de categorías y les asigna su rol en la sociedad. Las consecuencias de este "pensamiento heterosexual», como diría Monique Wittig, no solo extienden su dominio en el ámbito de los afectos, no es una mera ordenación del deseo, sino que se prefigura como una institución cultural y política que permea todos y cada uno de los ámbitos de nuestra realidad (49). Es, por tanto, el principio creador del que emana todo. De esta manera, el hombre heterosexual sirve como modelo para «explicar el mundo» (Guasch, La crisis 17). Siguiendo dicho precepto, ni las mujeres ni los homosexuales ni cualquier otra minoría sexual pueden definirse según criterios propios, no pueden autodeterminarse. Ello se debe a que este sistema se ha erigido históricamente como único por la premisa esencialista de la que parte, la cual ha posibilitado naturalizar todas las conductas humanas. Así, la relación sexoafectiva entre el hombre y la mujer «es universal y forma parte de la naturaleza humana» (Guasch, La crisis 18). El eje en torno al cual gravita esta forma de organización es de carácter dialéctico, se nutre de la tensión opositiva entre lo uno y lo otro, "está fundada sobre la necesidad del otro/diferente en todos los niveles», requiere del concepto de 'diferencia' para sostenerse (Wittig 53). Si lo heterosexual es la unidad, lo existente, lo biológico, todo aquello que no se ajuste a este esquema queda dentro del ámbito de lo desviado, de lo ilegítimo. La idea de diferencia (de la mujer con respecto al hombre, del gay con respecto al heterosexual) es la que, en definitiva, mantiene las relaciones de dominación que tanto caracterizan a este régimen.

El modelo heterosexual promueve una sociedad ordenada, lógica y cartesiana apuntalada sobre cuatro pilares fundamentales: "adultismo, sexismo, misoginia y homofobia» (Guasch, La crisis 23). Esto conlleva que solo ostentan el poder aquellos sujetos de edad adulta -recordemos la incapacidad a la que Occidente siempre ha condenado a mayores y niños- que asuman el rol de género asignado naturalmente. El resto queda a merced del gobierno de los que poseen esos privilegios. Por ello, algunos sectores o minorías acaban siendo apartados o negados. En cuanto a la gestión de esas identidades otras, hemos de decir que las posibilidades son limitadas: se puede ocultar y negar esa identidad para así no sufrir represalias ni señalamientos o se puede aceptar y asumir la propia condición. En el caso de Luisgé Martín, veremos un viaje que parte desde la completa negación de su propia naturaleza a la reivindicación de su diferencia. Este esquema viático es una estructura evidenciable en toda autobiografía, similar al que vemos en las novelas de aprendizaje, también llamadas coming-of-age o bildungsroman. El autobiógrafo se lanza a la escritura persiguiendo cierto autoconocimiento; así lo muestra, llegado el momento, la voz del autor: «Por eso no sé bien, desde hace mucho tiempo, quién soy realmente. $\mathrm{O}$, mejor dicho, no sé quién habría llegado a ser si en todos aquellos años cardinales no hubiera tenido 
que mentir día tras día» (Martín, El amor 39). En su caso, el yo tiene una tarea más, debe aprender qué es el amor, sus nombres y formas, y para ello supera una serie de adversidades que lo van perfeccionando. Él mismo lo comenta, no tiene reparos en mostrar la urdimbre de su creación: "Como los grandes héroes literarios, había atravesado todo tipo de peligros y de tentaciones y había salido de ellos transformado» (Martín, El amor 12). La gran mayoría de las veces el recorrido es tortuoso y, como Lázaro de Tormes, cambiando de amo -aquí de amante-, encuentra poco a poco su camino hacia la madurez. El personaje empieza siendo una cucaracha, deforme, solitaria e infecta, y termina siendo un hombre felizmente casado. Para exhibir su concepción de raro y hacer expreso el estigma que recae sobre él, el autor madrileńo recurre a la metáfora del monstruo: «esta condición patógena era una amenaza social irremediable, una anomalía extraña y virulenta que me convertiría en un monstruo» (Martín, El amor 13).

Aunque pueda parecer lo contrario, la idea de la monstruosidad está estrechamente ligada a la concepción de norma que promueve la organización heterosexual. Ya lo comentamos antes: la diferencia es un valor fundamental para la estructura que promueve la heterosexualidad. El monstruo, por tanto, es un ser repudiado, pero útil, ya que posee una función social determinada: «es gracias al monstruo que las identidades y los cuerpos normales pueden definirse y comprenderse. El monstruo también posee un carácter redentor" (García 20). A través de su ejemplo y su rechazo, el sujeto heterosexual aprende cuál es el camino que debe seguirse $e^{4}$. Para evitar este escarnio, el monstruo, por lo general, permanece en el ámbito de lo privado, se oculta, hace de las sombras su hogar. Ese es el mecanismo que sigue Luisgé Martín. El descubrimiento de su naturaleza monstruosa llega durante su infancia, aquel día en el que Miguel Ángel, su amor de colegio, no acudió a la piscina tal y como habían acordado. Mientras intenta manejar su sentimiento de abandono y desasosiego, se produce la revelación:

En otras ocasiones había tenido ya pensamientos frágiles y fugaces de mí mismo infectado por esa enfermedad, pero aquel día fue la primera vez que comprendí sin engaños la médula del amor. La primera vez que pronuncié en voz alta las palabras terribles: «Soy homosexual» (Martín, El amor 19).

A partir de este momento, el yo presenta «la determinación de crear un disfraz» para protegerse de los otros (Martín, El amor 13). En el caso de nuestro particular Gregor Samsa, la creación de una máscara no se corresponde solo con ese afán de pasar desapercibido a ojos de la sociedad, sino que también revela una no aceptación de su propia condición homosexual, al fin y al cabo, «un monstruo es

${ }^{4}$ Un ejemplo de esto lo encontramos en la interesante función que Óscar Guasch le presupone al arquetipo del homosexual afeminado o marica dentro de la institución heterosexual: «el marica se convierte en un personaje socialmente útil, al transformarse en el punto de referencia respecto al cual el varón puede fijar sus rasgos viriles negándolos en otro» (La sociedad 53). 
la forma que cobra un miedo» (Fox 19). El disfraz se basa en emular el comportamiento hegemónico, el modelo, hasta que se convierta en algo natural y orgánico:

El disfraz se transforma en vestimenta y las invenciones pasan a ser cualidades reales. Los gestos dejan de ser impostados y se vuelven naturales. E incluso en algún momento, cuando el ejercicio de fingimiento es muy intenso y prolongado, los pensamientos se enmarañan o se difuminan hasta extraviar al propio impostor (Martín, El amor 38).

De este modo, evidenciamos cómo realiza todo un proceso de passing. En la Sociología, este fenómeno queda definido como toda aquella estrategia social que se utiliza para «ocultar» o enmascarar algún tipo de cuerpo o conducta no normativa «con el fin de evitar conflictos» (Guzmán y Platero 10). Lo más común es que se asimilen estereotipos dominantes. En el caso de Luisgé Martín, para enmascarar su naturaleza de "monstruo humano», como diría Foucault, asume el modelo de la masculinidad hegemónica (57). Dicho constructo ha sido ampliamente estudiado por grandes autores como David Gilmore. De todas las características que se le presuponen en las sociedades occidentales, la que más nos interesa es la de su rechazo hacia lo femenino, porque es la que explota el escritor para forjar su nueva máscara (Guasch, La crisis 123). En esta primera etapa, potencia sus «modales viriles» y se encarga de «eliminar de ellos cualquier rastro de feminidad» (Martín, El amor 36). Los mecanismos que utiliza para lograr su objetivo son variados: adopta una pose a lo Humphrey Bogart; comienza a fumar, «el tabaco fue para mí durante muchos años un disfraz que escondía mi timidez y engrandecía mi masculinidad»; realiza gestos rudos, «me apretaba la bragueta con vulgaridad, sosteniendo los genitales con la mano abierta. Y cuando estaba en la calle o en el campo, escupía continuamente, áspero, desabrido, grosero", y, por supuesto, modula su expresión verbal, profiere insultos, palabras soeces, ya que «los maricas, según todos los clichés, usaban un léxico relamido y cursi, de modo que un blasfemador maldiciente debería ser, en justo correlato, el macho armonioso e indudable» (Martín, El amor 37). Con esto, el yo de su juventud se convierte en un completo actor, capaz de usar una máscara u otra dependiendo de su público. Así, con unos se hace «pasar por intelectual, despreciando todo lo que tuviera que ver con los instintos y dando a entender, por lo tanto, que mi reino no era de este mundo», mientras que con otros «exageraba mi impericia de seductor o mi fealdad, permitiéndoles que alardearan con altanería de sus conquistas» (Martín, El amor 38). Esta modulación de la identidad responde a la concepción del género como acto performativo tal y como defienden autoras como Judith Butler. En el caso de nuestro escritor, la construcción de su masculinidad estribaría, en el fondo, en una «actuación» constante.

El teatro que representa es para los otros, es su forma de relacionarse públicamente. En el ámbito privado, donde habita el monstruo junto con el prejuicio y la negación de su ser, nos encontramos una situación paralela. Poniendo a Dios por testigo, como Escarlata O'Hara, hace un solemne juramento: «en 1977, a los quince años de edad, cuando tuve la certeza definitiva de que era homosexual, me juré a mí mismo, aterrado, que nadie lo sabría nunca» (Martín, El amor 12). El poso camp 
de esta referencia no oculta el verdadero trasfondo de la acción. Luisgé Martín se condena a sí mismo al ostracismo. El sujeto se pliega sobre sí mismo, niega su verdadera identidad en todos los niveles de la vida:

Yo pasé aquellos años encerrado perseverantemente en mí mismo. Llevaba una vida de apariencia normal, sin soledades monásticas ni extravagancias de excéntrico, pero en lo que se refería a los asuntos del corazón y de la carne los días pasaban inmóviles, sin acontecimientos ni sorpresas (Martín, El amor 62).

La descrita es una situación análoga a la que se vive en todos esos regímenes dictatoriales en los que la voz individual no se puede expresar. Martín conoce a la perfección ese exilio interior, «mi temor de judío en la Alemania nazi, de comunista en el Chile de Pinochet o de burgués en la Camboya polpotiana se manifestó con signos de brutalidad» (El amor 146). El miedo a ser descubierto es tal que ni siquiera se atreve a exteriorizarlo a través de la escritura. Comienza, así, un periodo de autocensura en el que borra cualquier signo de su identidad homosexual. No manifiesta explícitamente su condición ni en las cartas, «me asustaba dejar un testimonio caligrafiado de mi puño y letra en manos de un desconocido. El terror era más grande que la pasión que sentía», ni en sus primeros ejercicios narrativos:

En ninguna de ellas, en todo caso, ni en ninguno de los cuentos que escribí también en esa época, aparecían personajes homófilos, reflexiones acerca de los secretos de la intimidad o señales argumentales que pudieran interpretarse en clave confesional. En ninguna de ellas aparecía la punta de un hilo del que tirar para desovillar la madeja. El secreto estaba guardado (Martín, El amor 35).

Su obsesión por las apariencias, por ser normal, por el silencio, es tal que, como ya hemos visto con anterioridad, recurre a diferentes tipos de terapias con el fin de acallar esa parte monstruosa que hay en su interior. Su único propósito es «ser heterosexual» debido a que en su mente operan dos ecuaciones maniqueas: la homosexualidad encarna todo lo negativo (tristeza, soledad, suicidio), frente a lo heterosexual, que es lo luminoso, lo feliz, lo correcto (Martín, El amor 104). Prueba con todo remedio posible, desde tarotistas, «con la ayuda de un especialista en tarot al que he acudido, estoy tratando de recuperar mi propio ser y la serenidad que perdí al volver de Torrevieja», hasta expertos en psicoanálisis, "yo, por mi parte, acudí a un psicoanalista de la escuela ortodoxa para tratar de curar mis padecimientos", pasando por la terapia conductista, «la filosofía de la terapia era muy simple: asociar el erotismo masculino con sensaciones desagradables y el erotismo femenino con sensaciones placenteras» (Martín, El amor 95-105). La fantasía heterosexual nos deja interesantes pasajes en sus diarios que él mismo cita:

Mi componente heterosexual es ya muy fuerte. He tenido posibilidad de comprobarlo hoy mismo. En una cena con unos amigos me puse un poco borracho y me hubiera dado igual un hombre que una mujer. Soy capaz de acostarme con una chica. Creo que todo va a ir bien, muy bien, y sería un sueńo si dentro de unos años, a finales de 1983, pudiera escribir en otro diario que por fin soy feliz (Martín, El amor 110). 
Como podemos comprobar, entre mente y cuerpo se establece una escisión. $\mathrm{El}$ autor plantea, entonces, un conflicto interno, una fractura o desfase entre su yo deseante -báquico- y su yo recto, fiel al deber, su yo apolíneo. Como bien propone D.A. Miller en su ensayo -y que nosotros recogemos a partir de Kosofsky Sedgwick-, el secreto es una práctica en la que «se establecen oposiciones de privado/público, dentro/fuera, sujeto/objeto y se mantiene inviolada la santidad de su primer término" (92). Ese término inmaculado es el que se impone ante la sociedad, el que crea la máscara. Ante el auditorio, actúa y se transforma en un joven de pose pusilánime, demasiado intelectual para los afectos. Por su parte, el deseo se mueve de manera subrepticia, en las sombras. En determinadas ocasiones, las ansias de la carne se imponen por encima del prístino disfraz. Hay varios ejemplos de lo que comentamos.

El primero se corresponde con la compra de revistas de carácter erótico como podría ser el magazín Party. La publicación barcelonesa contaba con una sección de desnudos masculinos, artículos donde la homosexualidad adquiría una valoración positiva y un consultorio amoroso dirigido por Luis Arconada, De tú a tú, en el que nuestro protagonista pudo comprobar que no estaba solo: «En aquellas páginas leí por primera vez historias conmovedoras de personas - de hombres- que sentían el mismo extravío que yo» (Martín, El amor 55).

El siguiente ejemplo está muy relacionado con esta última cuestión. Llegado el momento, la soledad se vuelve una losa demasiado pesada, por eso utiliza los anuncios por palabras de los periódicos para encontrar a otras personas de su misma condición: «era el primer método real que descubría para conocer a personas semejantes a mí; el primer camino hacia la guarida de los monstruos» (Martín, El amor 60). Es así como se suceden una batería de nombres y cuerpos que hasta el autor recuerda con dificultad.

En el tercer y último caso podemos apreciar cómo hay momentos en los que la máscara se quiebra y los instintos se apoderan del cuerpo. Nos referimos a esas secuencias fundamentales en las que el escritor participa del circuito de sociabilización homosexual de la época. Carcomido por el deseo y siempre vigilante, el yo recorre emplazamientos configurados para la satisfacción de la carne: «ahí no había que buscar el amor, sino el desahogo sexual, la eyaculación intemperante, y para eso no necesitaba excusas morales» (Martín, El amor 188). Estos son lugares visibles, comunes, como los urinarios de la estación madrileña de Atocha o los cines Carretas, Odeón o Condado, a los que se les superponen otros significados. Son espacios que se resignifican por el uso. Foucault los denominó heterotopias. Lo interesante de esta espacialidad otra es que «escapa a espacios de poder, de saberes hegemónicos, de discursos organizados» (Toro-Zambrano 36). De este modo, la única ley impuesta es la del goce. Las prácticas sexuales llevadas a cabo en dichas localizaciones no deben ser entendidas como una aceptación -momentánea- de la homosexualidad, sino todo lo contrario. En los baños o en los cines las experiencias que se viven son, en su gran mayoría, "preidentitarias», es decir, el sujeto no ha asumido su condición y recurre a los márgenes para encontrar algo que lo satisfaga (Llamas y Vidarte 50). Luego, vuelve la máscara.

Todo lo que hemos comentado hasta ahora nos muestra el efecto que los discursos hegemónicos tienen sobre el individuo, cómo estos se interiorizan, se apre- 
henden y, por supuesto, se reproducen. La identidad que perfila Luisgé Martín a la hora de hablar de su infancia, juventud y parte de su vida adulta es la de un yo aterrado por la soledad, dividido entre lo que quiere y lo que debe, que carga consigo prejuicios y modos por completo homofóbicos.

\subsection{Gueto, subcultura y HOMOFObia: El YO Y LA COMUNidAD}

El uso de la metáfora del monstruo es revelador, ya que aglutina dos tendencias claras y complementarias: por un lado, el proceso de categorización del pensamiento heterosexual que concibe la identidad gay como aberrante y, por otro, la aceptación del sujeto de dicho esquema. El insecto asume para sí el modelo impuesto desde todos los órdenes y esferas de la sociedad como verdadero y natural. De este modo, el sujeto hace suyos una serie de preceptos que lo niegan. Como hemos establecido ya en apartados anteriores, el sistema heterosexual tiene como "característica básica» la homofobia (Guasch, La crisis 131). Cuando hablamos de homofobia no nos referimos exclusivamente a "odiar, temer o estigmatizar a los homosexuales», sino también al «miedo y la inseguridad que invade a los varones ante la posibilidad de amar a otros varones» (Guasch, La crisis 131).

En su afán por alcanzar ese ideal heterosexual que tanto ansía, el yo monstruoso de Luisgé Martín utiliza una serie de estrategias de raigambre homófoba. Él mismo lo dice en una lúcida analogía, «los mejores predicadores del machismo, como se sabe, han sido algunas mujeres, y los mayores paladines de la homofobia han sido, a lo largo de la historia, los homosexuales» (Martín, El amor 184). Los mecanismos de rechazo al homosexual que podemos ver en El amor del revés van desde insinuaciones veladas hasta reflexiones explícitas. Una de las concepciones más prejuiciosas que podemos notificar es la categorización del individuo gay como hipercuerpo ${ }^{5}$. Este término hace referencia a la forma de percibir al sujeto homosexual como un ente que no tiene mayor realización que la carne, o sea, solo puede existir en el contexto de «la práctica sexual» (Llamas 153). Esa es su misión y objetivo en la vida. Su ser puede hacerse efectivo, alcanzar la plenitud, únicamente a través de la experiencia corpórea. El resto de dimensiones de lo humano -los planos, por ejemplo, de la ética y la política- quedan reservadas para aquellos cuya conducta no es bestial, sino intelectual. Los homosexuales tienen el sexo; los heterosexuales el amor. Por eso, en este sistema, «a la mayoría de los varones gays se les hace difícil amar a otros varones y reducen a terminología sexual la expresión de sus afectos» (Guasch, La crisis 132). La hipersexualización del cuerpo del homosexual es una respuesta de la heteronorma a la transgresión legal, biológica y cultural que suponen este tipo de sujetos. En esencia, el hipercuerpo es producto

${ }^{5}$ La reducción del individuo a la categoría de hipercuerpo no afecta en exclusiva a los homosexuales. El esquema de pensamiento en el que la mujer adquiere su máxima realización en la maternidad bebe también de la noción de hipercuerpo. 
de esa sociedad castradora que se empeña en separar el plano público del privado, la razón del deseo. Estas consideraciones permean, también, al ambiente gay. Nuestro autor, que ha hecho suya esta idea, comenta que «lo importante es el amor, no la lascivia» (Martín, El amor 13). Su aplicación, como podemos comprobar, genera cierta superioridad moral en aquellos que reniegan de la dimensión carnal y se entregan a lo intelectivo:

Durante muchos años me negué a entrar en los bares de ambiente argumentando, con necesidad, que todos los homosexuales que los frecuentaban eran unos degenerados disolutos con un solo propósito: la lujuria. Yo, en cambio, buscaba el amor. Ellos eran rijosos y yo era puro. Ellos eran inconscientes y yo era tenaz (Martín, Elamor 183).

La suma de prejuicios como el que hemos resaltado va calando en el imaginario colectivo. Así, los gais que todavía no han hecho pública su confesión, los que siguen en el armario, ven en sus iguales un objeto de rechazo. Necesitan de esa negación para evitar cualquier señalamiento o vínculo. El odio puede ir dirigido hacia sujetos individuales o hacia ideas como la de gueto, subcultura gay o cualquier otra manera de designar la unión colectiva de homosexuales. Estas últimas son, sin lugar a dudas, uno de los principales objetivos de ese yo monstruoso que no concibe la necesidad de un gueto o de una agrupación:

Los homosexuales reprimidos y canónicos solíamos emplear un argumento de naturaleza social: «Yo no quiero vivir en un gueto». ¿Quién podía querer vivir en un gueto? Enseguida venían a la mente las imágenes de los judíos de Varsovia o de Lodz encerrados y despojados de su humanidad. Y aun más: el gueto era la antesala de la deportación, del hacinamiento en barracones, del hambre, de la cámara de gas. ¿QQuién podía querer vivir en un gueto? (Martín, El amor 184).

Actualmente, en las sociedades democráticas, el gueto y la subcultura gay no se entienden en clave de exclusión o aislamiento, sino todo lo contrario. Debido a la represión histórica que este y otros colectivos han sufrido, dichos lugares se prefiguran como espacios que otorgan a todos aquellos que participen de él cierta protección con respecto a "las presiones del entorno" (Guasch, La crisis 32). Lo interesante del ambiente es que "ofrece espacios de interacción» en los que una sociabilización sana y sin peligros es posible (Guasch, La crisis 33).

Aunque en un principio el personaje de Luisgé Martín se muestra reacio, con el paso de los años sufre un proceso de "resubjetivación", es decir, el autor reinventa y redefine los límites de su propia identidad, llegando, como es su caso, a superar algunos esquemas mentales que durante etapas anteriores de su vida lo habían constreñido (Eribon 18). Empieza la metamorfosis inversa de Samsa o, si seguimos las palabras del escritor, «el desnudamiento de la cucaracha» (Martín, El amor 82). Este comienza con la exhibición pública de sus afectos en locales de ambiente. Su inmersión, su reinvención identitaria, tiene también un aire performativo. Asumido el rol de monstruo, de hombre-secreto, no puede tirar por tierra todos sus avances por aparentar ser normal, por ello, debe simular que sus amigos gais son los que lo 
introducen en este nuevo mundo que, con el tiempo, acaba fascinándole ${ }^{6}$. Es forzado a aceptar esa identidad, no es un acto voluntario. Aquí el ejemplo:

Yo en realidad deseaba tener una vida gay, pero necesitaba, de nuevo, que fuera en contra de mi voluntad. Deseaba cenar en esos restaurantes, ir a tiendas de homosexuales, dormir en hoteles exclusivos y vivir dentro de los perímetros del gueto, pero no encontraba arquitectura intelectual que sostuviera esas aspiraciones (Martín, El amor 255).

Aún con miedo a la delación, nuestro protagonista se sumerge en el ambiente gay de la capital. Una vez pasada la primera noche, la prueba de fuego, vinieron muchas más, tantas que al final se acabó convirtiendo en toda una personalidad de la noche madrileńa de los ochenta y noventa: «nos conocían todos los camareros, nos dejaban entrar saltándonos las colas y los controles, nos invitaban a las copas, nos contaban las nuevas noticias o los comadreos [...] y nos dejaban permanecer dentro del local cuando ya se había cerrado» (Martín, El amor 203). A ojos del escritor, los excesos y las correrías, la felicidad vivida, convierten el barrio de Chueca, antes emplazamiento de lo nefando, «en la patria que jamás había tenido hasta entonces» (Martín, El amor 196). La cucaracha ha encontrado a sus semejantes y va más allá al reconocerlos como tales. Se forja, por fin, cierto vínculo de pertenencia para con el colectivo, antaño diana de su desdén y prejuicio. Hemos de tener en cuenta que esta ligadura no es, al menos todavía, tan profunda. Simplemente se fundamenta en los placeres, en el divertimiento, en lo superfluo y banal. Esta postura fue la tónica reinante en el ambiente gay español durante las últimas décadas del siglo xx. Liberados de las cadenas del franquismo, reconocidos por el sistema heterosexual y autodeterminados como grupo social, recordemos que ya Chueca es toda una institución, el activismo de los primeros años de la democracia decayó sobremanera. Algunos autores hablan de «embriaguez gay" para referirse a la situación de despolitización generalizada que se vivió en la década de los noventa (Guasch, La crisis 28). Luisgé Martín lo refleja con certeza:

La causa de los homosexuales, sin embargo, no me conmovía. [...] Soñaba, como siempre, con encontrar un hombre al que amar para el resto de la vida, pero dentro de ese sueńo no cabía el hecho de que conviviéramos juntos y celebráramos públicamente nuestra relación: imaginaba -si acaso imaginaba algo con tanta precisión- que cada uno tendría una casa, que nuestros objetos estarían separados, que solo algunos amigos cercanos sabrían toda la verdad de nuestro trato, que la mayoría de las noches yo dormiría solo. Y esa idea no me impacientaba ni me causaba indignación (Martín, El amor 198-199).

${ }^{6}$ Los motivos de este cambio de perspectiva no responden solo a la presión de grupo. Hemos de matizar que los viajes que realizó en su juventud a Francia y a Holanda desempeñaron un papel decisivo. Al igual que Juan Goytisolo en las medinas marroquíes, Luisgé Martín se reeduca a partir del ejemplo foráneo. 
Tras la crisis del sida, esta situación fue insostenible. El colectivo LGBTI tuvo que repensarse, redefinirse, para así hacer frente a la gran tragedia. Ante la falta de atención de los gobiernos, se optó por contar las historias de aquellos cuerpos infectos, de nuevo monstruosos, que morían por miles día a día. Es así como lo privado se volvió político: «las alcobas se convirtieron a veces en barricadas. Hubo un instante en mi biografía -impreciso, sin fecha, a finales de siglo- en el que la eyaculación se transformó para mí en un asunto político" (Martín, El amor 256). Este es uno de los centros de El amor del revés: hacer de lo íntimo un acto de reivindicación, crear un testimonio que resuene en los lectores y les sirva de ejemplo. Esta toma de conciencia, este acto de empoderamiento, es el que convirtió a la cucaracha en humano. Gracias a este último ejercicio de autoaceptación, nuestro protagonista pudo dejar atrás los caparazones, las antenas, el miedo y la soledad y encontrar, por fin, el amor.

\section{CONCLUSIÓN}

La propuesta de Luisgé Martín es una fiel continuadora del legado que otros autores gais, como Juan Goytisolo o Terenci Moix, han dejado en nuestra literatura.

Gran parte de la riqueza de la obra del madrileńo radica en su capacidad para sintetizar todos los discursos que, de una manera u otra, le influyeron en su tiempo. De todas las definiciones del homosexual que proporcionamos hemos comprobado que, por su formación y ambiente, la predicada por el férreo catolicismo del régimen es la que mayor calado presentó en su vida. La naturaleza punible de la práctica homosexual engendró, como en El sueño de la razón goyesco, una identidad monstruosa. La metáfora del monstruo no solo debe ser entendida como una autorrepresentación de la diferencia del autor, sino como una forma de asimilar los prejuicios del entorno. Para sobrevivir a ello, el insecto debe adaptarse. De ahí su máscara. El personaje desarrolla una pose, basada en la adopción de un gesto masculino, que se adecua a los principios básicos del pensamiento heterosexual.

Nuestro Gregor Samsa hace todo un camino de perfección en el que, poco a poco, va desgajándose de su exoesqueleto: de su fingida e intelectual asexualidad, pasa a una heterosexualidad impostada, para terminar, por fin, aceptando su verdadero deseo homosexual; de su pudor por lo erótico nace toda una filosofía personal que gira en torno a conocer la verdadera naturaleza humana a través de la carne; de su acérrima homofobia, surge un sujeto comprometido que, con ciertas limitaciones, se sensibiliza con la causa de su colectivo.

Como ya hemos podido comprobar, los elementos identitarios y códigos que maneja el autor madrileño a lo largo de su metamorfosis lo adscriben a un modelo de expresión homosexual concreto. Si bien es cierto que su afán por lo marginal y abyecto lo acerca al «modelo malditista», su constante defensa de la normalidad, leitmotiv de toda la obra, lo vincula con el arquetipo del «homófilo», es decir, con aquel cuya máxima preocupación es «la integración del homosexual en la sociedad» (Mira 25). De manera análoga, podemos concluir, también, que El amor del revés (2016) es un ejemplo de lo que Robert Richmond Ellis denomina «gay autobiography» (13-14). Si bien determinados aspectos de la escritura de Luisgé Martín, 
como la concreción históricocultural de su discurso o esa impronta política que se deja entrever al final de la obra, lo acercan a la idea de "homobiography", hemos de establecer que no son cuestiones que presenten un carácter central en su escritura. Por encima de ellas, encontramos elementos definitorios de la "gay autobiography» como podrían ser la obsesión que presenta el yo con conceptos como el de diferencia o el de norma, la perdurabilidad incuestionable del binomio hetero/homo y, por supuesto, las ansias de reafirmación y libertad de esa identidad gay antańo reprimida.

De una manera o de otra, en estas «memorias sodomitas» hallamos un importante testimonio literario en el que el deseo y el cuerpo homosexual son el principal locus de la creación (Martín, El amor 127).

ReCiBIDO: 1-10-2020; ACEPTADO: 21-1-2021 


\section{BIBLIOGRAFÍA}

Aliaga, Juan y Cortés, José. Identidad y diferencia. Sobre la cultura gay en España. Madrid: Egales, 1997.

Brubaker, Roger y Cooper, Frederick. «Beyond 'identity'». Theory and Society, 29:1 (2000), pp. 1-47. (https://eclass.aegean.gr/modules/document/file.php/SA200/Brubaker\%20\%26\%20Cooper\%202000.pdf).

Butler, Judith. El género en disputa. Feminismo y subversión de la identidad. México: Paidós, 2001.

Caballé, Anna. Narcisos de tinta: ensayos sobre literatura autobiográfica en lengua castellana (siglos XIX Y XX). Málaga: Megazul, 1995.

Cuadra, Bonifacio de la. «El Constitucional mantiene fuera de servicio a un capitán condenado por homosexual». El País, 30 de diciembre de 1988, 4 párrs. (https://elpais.com/diario/1988/12/30/sociedad/599439606_850215.html).

Davis, Colin y Burdiel, Isabel. (eds.). El otro, el mismo. Biografía y autobiografía en Europa (siglos XVII-XX). Valencia: Publicaciones de la Universitat de València, 2005.

Durán López, Fernando. Catálogo comentado de la autobiografía española (siglos XVIII y XIX). Madrid: Ollero \& Ramos Editores, 1997.

Ellis, Robert Richmond. The Hispanic Homograph: Gay Self-Representation in Contemporary Spanish Autobiography. Illinois: University of Illinois Press, 1997.

Eribon, Didier. Reflexiones sobre la cuestión gay. Barcelona: Anagrama, 2001.

Foucault, Michel. Los anormales. Madrid: Akal, 2001.

Fox, Charlie. Este joven monstruo. Barcelona: Alpha Decay, 2017.

García, Daniel. Rara avis. Una teoría queer impolitica. Santa Cruz de Tenerife: Editorial Melusina, 2016.

Gilmore, David. Hacerse hombre: concepciones culturales de la masculinidad. Barcelona: Paidós, 1994.

Goffman, Erving. Estigma. La identidad deteriorada. Buenos Aires: Amorrortu editores, 1970.

Goytisolo, Juan. Coto vedado. Madrid: Alianza, 2018.

Guasch, Óscar. La sociedad rosa. Barcelona: Anagrama, 1991.

GuAsch, Óscar. La crisis de la heterosexualidad. Barcelona: Laertes, 2007.

Guzmán, Paco y Platero, Lucas. «Passing, enmascaramiento y estrategias identitarias: diversidades funcionales y sexualidades no-normativas», en Platero, Lucas (ed.), Intersecciones: cuerpos y sexualidades en la encrucijada, Barcelona: Bellaterra, 2012, pp. 1-24. (http://digital.csic.es/ bitstream/10261/78447/1/PASSING\%20ENMASCARAMIENTO\%20Y\%20ESTRATEGIAS\%20IDENTITARIAS.pdf).

Kosofsky, Eve. Epistemología del armario. Barcelona: Ediciones de la Tempestad, 1998.

Ley DE VAGOS y MALEANTEs, 17 de julio de 1954. (https://www.boe.es/datos/pdfs/BOE/1954/198/ A04862-04862.pdf).

Llamas, Ricardo. «La reconstrucción del cuerpo homosexual en tiempos del sida». REIS, 68 (1995), pp. 141-171. (http://www.reis.cis.es/REIS/PDF/REIS_068_09.pdf).

Llamas, Ricardo y Vidarte, Francisco. Homografías. Madrid: Espasa Calpe, 1999.

Loureiro, Ángel. «Problemas teóricos de la autobiografía». Anthropos, 29 (1991), pp. 2-8. 
Martín, Luisgé. Los amores confiados. Madrid: Alfaguara, 2005.

Martín, Luisgé. Las manos cortadas. Madrid: Alfaguara, 2009.

Martín, Luisgé. La misma ciudad. Barcelona: Anagrama, 2013.

Martín, Luisgé. La vida equivocada. Barcelona: Anagrama, 2015.

MARTín, Luisgé. El amor del revés. Barcelona: Anagrama, 2016.

Mira, Alberto. De Sodoma a Chueca. Una historia cultural de la homosexualidad en España en el siglo XX. Madrid: Egales, 2004.

Morx, Terenci. El peso de la paja 2. El beso de Peter Pan. Barcelona: Plaza y Janés,1993.

RICH, Adrienne. «Heterosexualidad obligatoria y existencia lesbiana (1980)» [I]. DUODA, 10 (1996), pp. 15-43. (https://www.raco.cat/index.php/DUODA/article/view/62008/90505).

Romera Castillo, José. De primera mano. Sobre la escritura autobiográfica en España (siglo XX). Madrid: Visor, 2006.

Sanz Villanueva, Santos. «La conquista de la identidad». Zenda, 4 de octubre de 2016, 6 párrs. (https://www.zendalibros.com/la-conquista-la-identidad/).

Toro-Zambrano, María. «El concepto de heterotopía en Michel Foucault». Cuestiones de Filosofia, 3:21 (2017), pp. 19-41. (https://revistas.uptc.edu.co/index.php/cuestiones_filosofia/ article/view/7707).

Wittig, Monique. El pensamiento heterosexual y otros ensayos. Madrid: Egales, 2006.

Woods, Gregory. Historia de la Literatura Gay. La tradición masculina. Madrid: Akal, 2001. 
